\title{
EL IDOLO DE «EL LOMO» (COGOLLUDO, GUADALAJARA)
}

\author{
POR \\ JESUS VALIENTE MALLA (*)
}

\begin{abstract}
RESUMEN Se estudia un bloque de piedra esculpido, procedente del poblado de EEl Lomon (Cogolludo, Guadalajara). Es un fragmento de estalagmita que, en su estado natural, podia sugerir una semejanza con los «ídolos ovoides», sobre guijarros, que se caracterizan por llevar una ancha acanaladura longitudinal. Esta sugerencia se completó por el procedimiento de tallar en la parte superior del bloque otra hendidura profunda que le confiere la apariencia de un kídolo de cuernos». Estas piezas de intencionalidad simbólica son propias de ambientes eneolíticos. El ídolo de Cogolludo apareció en una hoya que corresponde precisamente a la primera fase, eneolítica, del poblado, a juzgar por las cerámicas que la acompañaban. Para esta fase (El Lomo I) contamos con dos fechas radiocarbónicas en torno al año 2100 a.C.
\end{abstract}

ABSTRACT This paper discusses a carved stone found in El Lomo, a prehistoric settlement near Cogolludo (province of Guadalajara) in central Spain.

The natural shape, of the stalagmitic rock from which the idol of Cogolludo was made resembled some prehistoric pebbles in which a man-made mark along the middle suggests they were connected with some kind of fertility rite; in the case of the idol from El Lomo, this intention was reinforced by decorating the top of the stone with a perpendicular carving, making it resemble a horned idol.

The symbolic pieces are generally associated with Eneolithic ritual practices. The Cogolludo carving was found in a pit associated with potsherds corresponding to the first period of the site's occupation (El Lomo I). This phase is C-14 dated to about 2100 B.C.

El poblado de La Loma del Lomo (Cogolludo, Guadalajara) es uno de los exponentes más septentrionales del conjunto de asentamiento de la Edad del Bronce integrados por "hoyas" o "fondos de cabaña", cuya mayor densidad se sitúa sobre las terrazas de los afluentes y subafluentes del Tajo por su margen derecha, especialmente en los alrededores de Madrid (Fig. 1). Las hoyas del poblado de Cogolludo (Valiente Malla, 1983) se presentan claramente agrupadas en dos zonas; las de la zona A - la situada más a poniente- muestran unas características que sugieren claramente su utilización como vertederos; las de la zona B, en cambio, evidencian una utilización final como elementos de habitación, posiblemente con funciones diversas y complementarias (cocina, dormitorio, despensa...); estas hoyas se agruparían quizá bajo una cubierta de material liviano, del que únicamente subsisten las características pellas de barro con improntas de ramaje. Precisamente en la zona B

(") Profesor Titular de Historia Antigua. Universidad de Alcalá de Henares. 


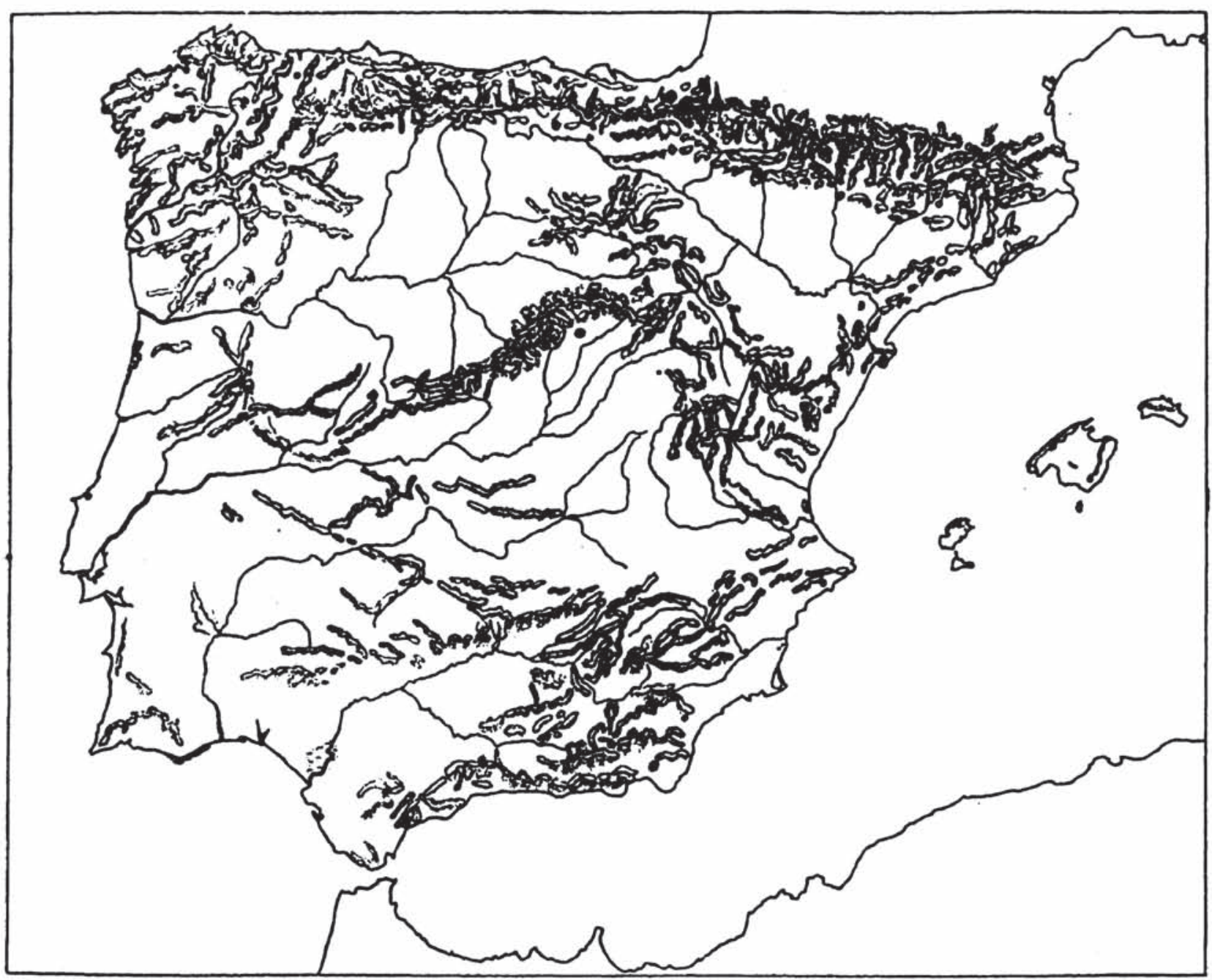

Fig. 1.- Mapa de situación de «El Lomo" (Cogolludo, Guadalajara).

han aparecido más de veinte enterramientos individuales, a propósito de los cuales cabe hablar de una extensión del rito kargárico" hacia el interior de la Península, dicho sea con todas las salvedades y a falta de las necesarias matizaciones (Valiente Malla, 1987).

El análisis de los resultados obtenidos durante las tres primeras campañas arqueológicas (19821984) ha permitido establecer, además de la división del poblado en zonas, un desarrollo del mismo a lo largo de un doble momento cultural y cronológico. La etapa más antigua corresponde al Eneolítico; sus rasgos definitorios más sobresalientes son las cerámicas lisas, con perfiles continuos o levemente sinuosos y superficies alisadas con un pulidor ancho que deja huellas en distintas direcciones. Estas cerámicas aparecen generalmente en hoyas de escasa profundidad y relativamente anchas, distintas de las que han aportado materiales característicos de un Bronce pleno, que son más profundas que anchas, si bien aparecen cortadas por pavimentos de material calcáreo que delimitan, en la parte superior de las hoyas, espacios útiles de proporciones semejantes a los que presentan los fondos más antiguos. La cronología que insinúa la comparación de estos dos conjuntos de hoyas con otros asentamientos de la inisma área cultural queda confirmada por cuatro fechas radiocarbónicas que sitúan el poblado de El Lomo entre 2100 y 1400 a.C.

Para el objeto de esta noticia, que es presentar una pieza lítica singular, interesa advertir que las hoyas más antiguas aparecen ahora irregularmente repartidas por las dos zonas que hemos señalado. 
En la zona A se sitúan sin ningún orden aparente entre las más recientes, mientras que en la zona $\mathrm{B}$ se alinean al margen norte del ámbito que hemos caracterizado como área de habitación. El dato es susceptible de una doble interpretación; podría ser indicativo de una estratigrafía horizontal, lo que significaría que el poblado se desarrolló a partir de una ligera elevación que marca el borde norte de la meseta en dirección al centro de la misma, o que a lo largo de la existencia del poblado se vaciaron y reexcavaron en profundidad las hoyas más antiguas para acondicionarlas a nuevas exigencias.

\section{LA HOYA 14E-1}

Entre las hoyas situadas en la zona marginal de la zona B, la que denominamos 14E-1 se singulariza por algunas de las piezas que proporcionó (Fig. 2). Es una cubeta ancha y poco profunda, de 1,40 m. de ancho por algo menos de $0,50 \mathrm{~m}$. de profundidad, excavada en un estrato de caliza blanda y compacta. Contenía un relleno homogéneo consistente en tierra de color ocre ceniciento.

Al igual que ocurre en casi todas las hoyas de la zona B, lo mismo antiguas que recientes, los materiales recuperados en ésta son ante todo de carácter doméstico: restos de un pavimento, algunas molederas de buen tamaño, de esquisto o arenisca, huesos de animales y, sobre todo, cerámicas, que presentan los rasgos habituales de las correspondientes a la fase más antigua del asentamiento: superficies bien alisadas con un pulidor que deja trazos anchos, o muy finamente brunidas, aunque no faltan las piezas de factura y acabados más toscos. Destacan en este conjunto varios fragmentos de un mismo recipiente que ostenta, al exterior del borde, una de las escasísimas decoraciones halladas en el yacimiento, concretamente un sencillo tema de medias lunas enlazadas por los picos, a modo de guirnalda, de trazo seguro y regular apenas marcado, al estilo de las decoraciones bruñidas (Fig. 3, núms. 2-6).

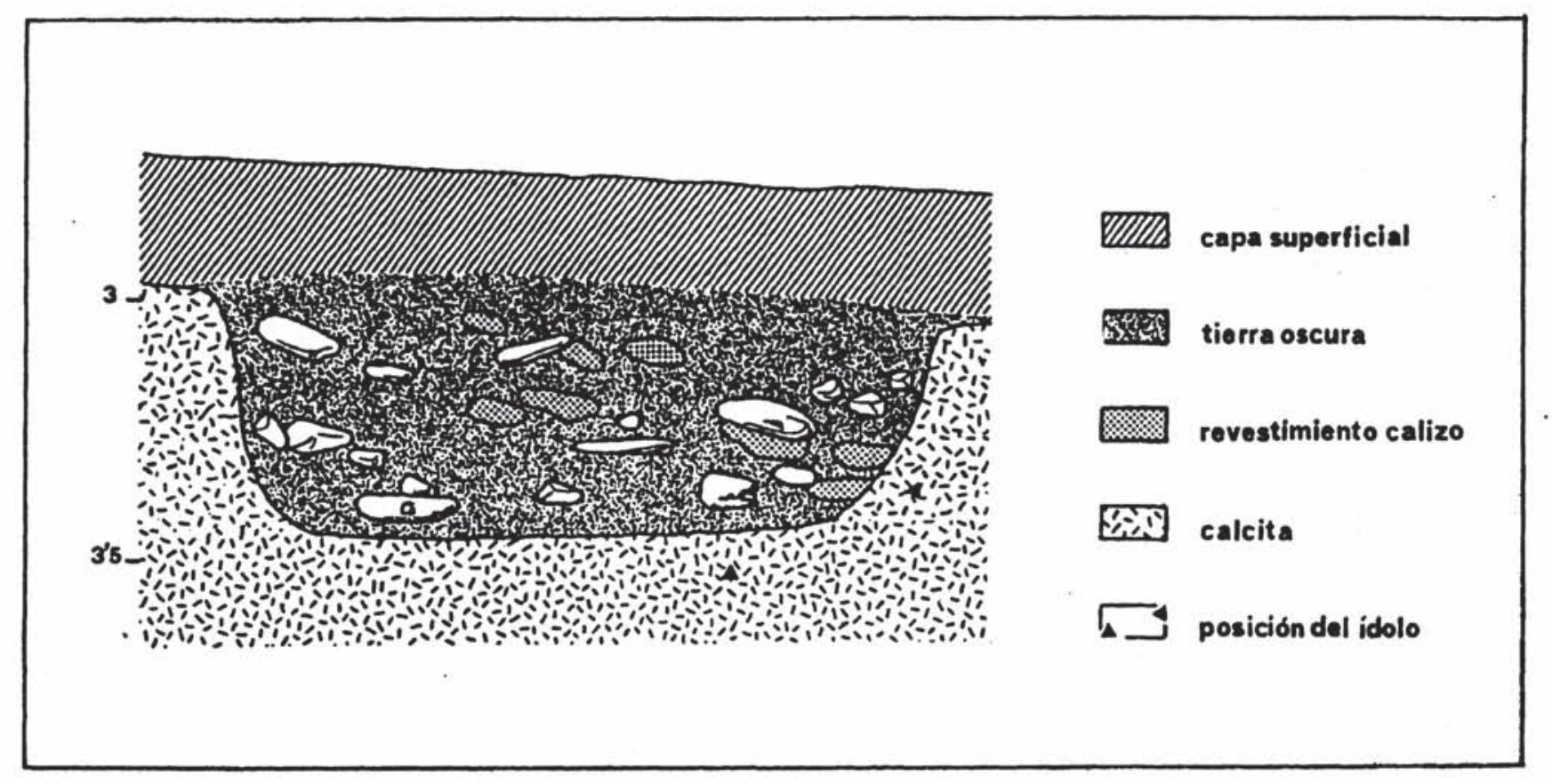

Fig. 2.- Estratigrafía de la hoya 14E-1 de «El Lomo" (Cogolludo, Guadalajara). 

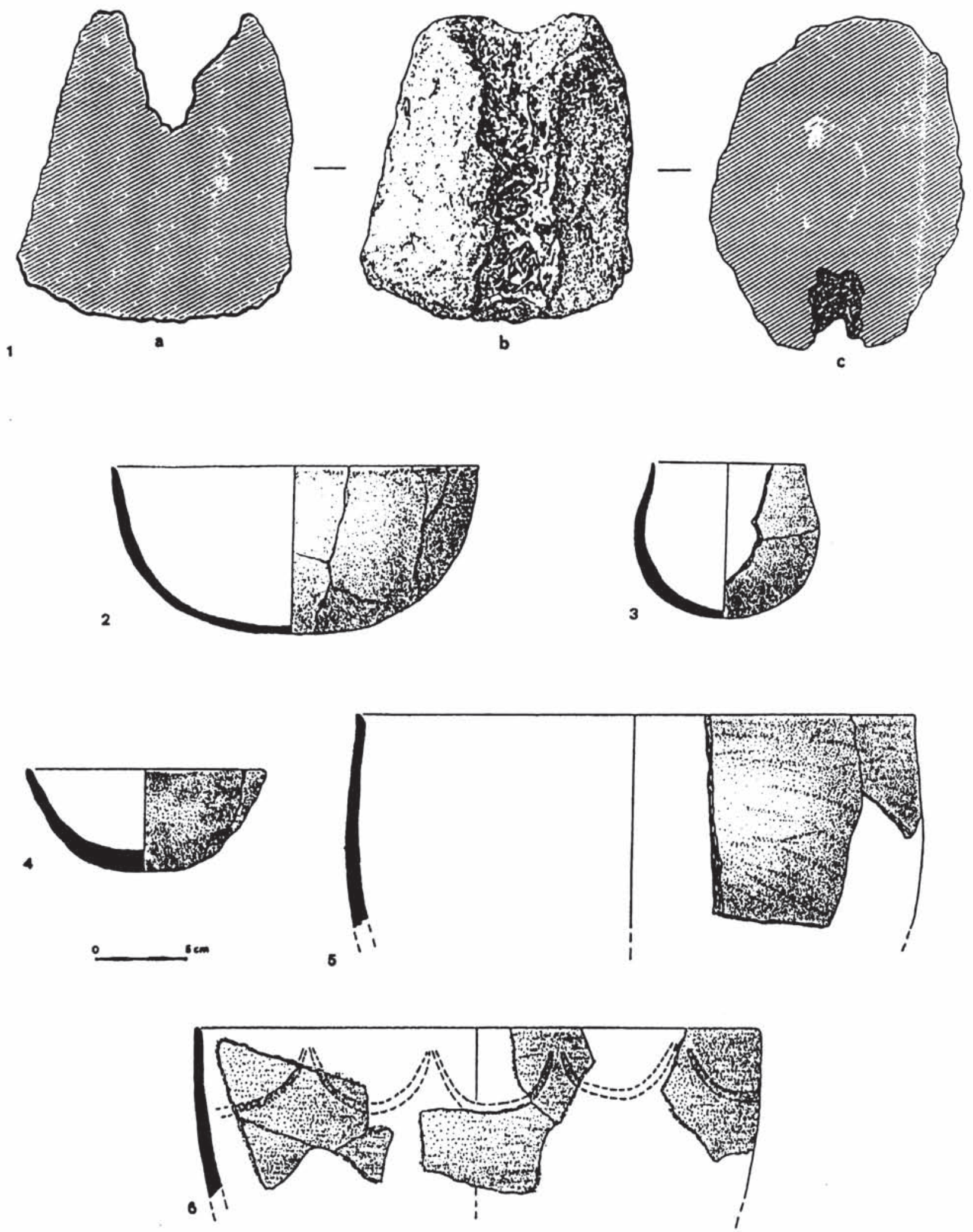

FIG. 3.- Materiales de la hoya 14E-1: idolo (1) y cerámicas (2-6) de «El Lomo" (Cogolludo, Guadalajara). 


\section{EL BLOQUE ESCULTORICO}

Es otra pieza singular recogida en esta hoya (Fig. 3, n. ${ }^{2} 1$ ). Se trata de un bloque natural de calcita muy pura (1), probablemente una estalagmita. Presenta forma troncocónica de base elíptica convexa; mide $166 \mathrm{~mm}$. de alto, $150 \mathrm{~mm}$. de ancho menor y $178 \mathrm{~mm}$. de ancho mayor en la base. El bloque original tiene en el lado que podemos considerar frontal una hendidura rellena de una formación esponjosa de la misma composición que el resto de la pieza. La labor escultórica (que afecta únicamente a las zonas marcadas con trazo grueso en la Fig. 3, n.․1, a) consistió en tallar la base con golpes someros y en practicar un rehundimiento en la zona superior a modo de surco profundo. En el reborde derecho de la hendidura frontal hay unas mellas que parecen debidas a roturas accidentales.

Para la interpretación cultural de esta pieza ha de tenerse en cuenta ante todo que nada indica que se trate de un "útil». No es un morillo, porque no presenta señal alguna de la acción del fuego, que, por otra parte, habría calcinado el bloque y provocado consecuentemente su desintegración. La forma de la hendidura tampoco se prestaría a utilizar el bloque como soporte de recipientes, ni muestra el pulimento que cabría esperar en un alisador. Se trataría, en definitiva, de una verdadera escultura de carácter simbólico, pero de un tipo peculiar, como indica el hecho mismo de que es una pieza realizada a partir de un material que, por sí mismo y en estado natural, remitía a cierto tipo de representaciones simbólicas. La intervención del escultor se limitaría a subrayar y completar la sugerencia que de por sí implicaban la forma, el volumen y las proporciones del bloque original, junto con la hendidura que mostraba en la zona frontal.

\section{EL IDOLO DE COGOLLUDO Y LOS IDOLOS CON ACANALADURAS}

Es precisamente este rasgo - la acanaladura que recorre verticalmente el frente del bloque- el elemento básico que permite comparar la escultura de Cogolludo con los llamados "ídolos ovoidales", cuyo rasgo diferenciador es precisamente un surco practicado generalmente sobre guijarros ovoides. No siempre se les ha asignado intencionalidad simbólica (Almagro Gorbea, 1973: 265-78; Figs. 64-65); hay autores que les atribuyen funcionalidades diversas (mazas, afiladores, etc.), incluso en los casos en que la presencia de una profusa decoración les confiere un cierto aire suntuario (Piñón Valera, Bueno Ramírez. 1985: 293-306). Para aclarar esta cuestión es ilustrativo el ídolo de Puig Pelegrí (Almagro Basch, 1970: 169-73), con una representación decididamente antropomórfica, que probablemente ostenta también el ídolo de Noceda, en este caso con la dualidad masculino-femenino repartida en ambas caras (Almagro Basch, 1971: 305-312). El ídolo de Puig Pelegrí ostenta una ancha acanaladura latitudinal; el de Noceda muestra en cada cara una estría longitudinal que no presenta mayor desgaste que los demás surcos que configuran el tema representado. No parece que en estos casos quepa hablar de utilitarismo, sino que se trata de piezas de clara intencionalidad simbólica y, más concretamente, por vía de sugerencia antropomórfica. Así lo confirma el tema representado en el ídolo de Ciudad Rodrigo, de tamaño mayor que el habitual en estas piezas, pero situado claramente en su misma línea significativa. En este caso, la representación antropomórfica se acerca más a lo naturalista y su identificación no ofrece duda alguna (Almagro Basch, 1969: 321322; Lám. I). El ídolo de Ciudad Rodrigo puede considerarse excepcional por su tono naturalista, a

(1) Su análisis ha sido realizado por la Dra. Ana M." de Andrés, del Instituto de Química Inorgánica «ELHUYAR», del C.S.I.C. 
diferencia del grado extremo de abstracción que se da, por ejemplo, en ejemplares de San Bartolomé de la Torre, Huelva (Garrido Roiz, 1971: 113-15; Fig. 12), entre los que hay un fragmento de cuarcita correspondiente a la cara superior de un guijarro ovoide muy abultado con ancha acanaladura que genera dos protuberancias que recuerdan la parte superior de los kidolos de cuernos"; la superficie muestra círculos y óvalos que se comparan con símbolos de la divinidad representada sobre un vaso de la sepultura I de Los Millares y con representaciones esquemáticas extremeñas. Otra pieza de San Bartolomé de la Torre, completa, de mármol, tiene forma ovoide y ostenta una ancha y profunda acanaladura longitudinal, con líneas perpendiculares a ambos lados. Se interpreta como una representación del sexo femenino, tema frecuente en círculos agrarios, "en los que la fecundidad de seres y plantas es parte integrante del complejo de ideas mágico-religiosas". Respondería a la misma idea que las figuraciones de los kidolos-placa». Una tercera pieza de la misma procedencia (Almagro Gorbea, 1973: 266-68; Fig. 64, n. ${ }^{9}$ ) es también de forma ovoide, con ancha acanaladura longitudinal y lineas convergentes a la misma, que aparecen también al dorso. La misma idea se materializaría en un ídolo de La Pijotilla (Badajoz), sobre guijarro ovoide, con ancha acanaladura hacia la que convergen por ambos lados lineas incisas, que se interpreta como representación de la vulva femenina. La cerámica que acompaña a la nutrida serie de idolos de La Pijotilla apunta a un horizonte calcolítico (Hurtado, 1980: 193-94; Fig. 13, e) (2).

Quizá entren también en este mismo orden de representaciones las pequeñas hachas votivas con escotadura o surcos como las procedentes de las terreras del río Henares (Valiente Malla, 1986: 200; Fig. 2, n. ${ }^{9}$ 1) y Palenzuela (Palencia), en ambientes de raiz eneolitica cuanto menos, a los que se asigna una cronologia entre 2000-1800 a.C. (Liz Callejo, 1975: 333-40; Fig. 6).

Resumiendo las anteriores consideraciones, parece incuestionable que en el conjunto de los "idolos ovoidales" ha de afirmarse una intencionalidad simbólica, al menos para una buena parte de estos objetos. La pieza de Cogolludo que estudiamos, por sus mismas características naturales, remitía a este tipo de plástica simbólica.

\section{EL IDOLO DE COGOLLUDO Y LOS «IDOLOS DE CUERNOS"}

Pero la intervención del escultor no se limitó a un mero acondicionamiento del bloque natural. Por el contrario, lo que de por sí sugería la hendidura frontal se subrayó tallando la parte superior, de forma que se acusaran las dos protuberancias laterales que confieren a la pieza una capacidad de sugerencia más intensa, que la aproxima a un grupo distinto de creaciones simbólicas. Nos referimos concretamente a los llamados uidolos de cuernos", cuyo estudio se inicia con la publicación de los hallazgos de Vila Nova de S. Pedro, correspondientes al Período I de aquel yacimiento según la periodización de H. N. Savory, es decir a la fase anterior a la construcción del gran bastión (Savory, 1972: 27-28; Fig. 4, núms. 1-3). Se describen en principio como utensilios (pes de fogareiro); están modelados en barro y tienen la base plana o ligeramente cóncava; llevan la parte superior hendida y perforaciones horizontales que atraviesan todo el bloque; Savory los relaciona con ídolos anatólicos, egeos y balkánicos, y los interpreta, junto con los copos canelados (Do Paço, 1959: 252. 260), como exponentes de un «horizonte de importaciones" que certificarían la conexión efectiva

(2) Subraya V. Hurtado la dificultad que se plantea a la hora de atribuir una significación precisa y la condición misma de objetos religiosos a algunas de estas piezas, y ello por varias razones, como el desconocimiento del contexto arqueológico en muchos casos y nuestra irremediable ignorancia acerca de la religiosidad megalítica. En este caso estarian especialmente los citados ídolos de San Bartolomé de la Torre y La Pijotilla, que podrían responder a una finalidad práctica, pero sin descartar la posibilidad de que se utilizaran ken ocasiones especiales, como ceremonias de mimesis ritual, pero muy difícilmente cabe considerarlas como símbolos de fertilidad o ídolos-vulvan. 
con el Próximo Oriente, problemática en la que ahora no entramos (Ramos Millán, 1981: 203-56). La interpretación de Savory fluctúa entre la caracterización como "soportes para espetones" o como «idolos espetones" (Savory, 1968: 137; Fig. 43, a-d).

K. Spindler halló fragmentos de piezas semejantes en Pico Agudo (Torres Vedras, Lisboa) y propone una reconstrucción de las mismas a partir de la revisión de una pieza de Vila Nova de S. Pedro anteriormente publicada por Savory (Spindler, 1971: 64; Fig. 6, núms. 37-39; 4, a y b). Las piezas de Pico Agudo serían realmente ídolos, a juzgar por el esquema de "ojos" que ostenta la de Vila Nova de S. Pedro y los antecedentes egeo-anatólicos que se les suponen. En tal sentido se cita un trabajo de Diamant y Rutter, si bien es cierto que estos autores reconocen carácter simbólico tan sólo a los "cuernos de consagración" cretenses, que incluso serian originalmente objetos domésticos posteriormente sacralizados (Diamant y Rutter, 1969: 175-76). Es de notar que los fragmentos de Pico Agudo presentan las protuberancias superiores no propiamente en forma de cuernos, sino a modo de muñones redondeados que acentúan la semejanza con otros elementos de indudable intención simbólica, los llamados *idolos-falangen, sobre tarsos habitualmente de grandes rumiantes, que se interpretan razonadamente como evocaciones de la feminidad en virtud de las decoraciones que a veces ostentan: triángulo sexual, tatuaje facial, ojos, líneas quebradas de los cabellos... en técnica de pintura, grabado o mixta (Almagro Gorbea, 1973: 153-168; Figs. 26-27).

Esta semejanza entre los «ídolos de cuernos" y los «ídolos falange» ha sido subrayada a propósito de las piezas aparecidas en Valencina de la Concepción (Sevilla), donde se han recuperado únicamente fragmentos, pero en cantidad suficiente para asegurar su identidad con las de otros yacimientos. Se rechaza en este caso la funcionalidad de "morillos", pues no presentan ni señales de fuego ni el desgaste que cabría esperar en la hendidura superior, de haber servido como soportes de espetones. Estas piezas aparecen en Valencina de la Concepción formando parte del relleno que colmataba los silos del poblado; son contemporáneas de otros elementos de carácter decididamente simbólico (ídolos antropomorfos, ídolos cilíndricos, ídolos placa, ídolos ovoides...) y juntos forman un riquísimo repertorio de alusiones a unas fuerzas que no controla el hombre, pero de las que depende absolutamente su existencia. Se enmarcan exclusivamente en los comienzos de la Edad de los Metales, en torno a la fecha del 2100 a.C., cuando los pozos y silo del poblado estaban ya en proceso de colmatación, antes de la fase campaniforme del yacimiento (Fernández Gómez, Oliva Alonso, 1980: 20-44; Figs. 9 y 10). Es de notar la coincidencia entre la fecha radiocarbónica de Valencina de la Concepción y las dos obtenidas para la fase más antigua de El Lomo de Cogolludo.

También para la ya citada pieza de Vila Nova de S. Pedro se admite, al menos, «una vaga alusión a los ídolos antropomórficos contemporáneos» (Savory, 1968: 137); esta alusión no sería realmente tan vaga, pues se trata de esquemas de "ojos" o "soles" (Spindler, 1971: 64) que aparecen plenamente desarrollados en los ídolos falange, en los realizados sobre metatarsos e incluso en las llamadas "cerámicas simbólicas" (Martín Socas y Camalich Massieu, 1982) a partir de la fase caracterizada por las grandes fortificaciones en Los Millares, Vila Nova de S. Pedro, Zambujal y establecimientos paralelos. De esta fase más avanzada hay en Vila Nova de S. Pedro una placa de barro que presenta el lado superior ligeramente rehundido en el centro y con la representación incisa del pubis femenino en la zona inferior (Savory, 1968: 160-62; Fig. 53, e); podria tratarse de un tipo intermedio, desde el punto de vista formal, entre los «idolos de cuernos" y los «ídolos placa», con lo que se confirmaría el carácter simbólico de los primeros. Por otra parte, esta pieza nos aporta un nuevo elemento para interpretar la escultura de Cogolludo, en el sentido de que la hendidura frontal que presentaba el bloque de piedra en estado natural habría sido vista por el escultor como una sugerencia del sexo femenino, que le remitía a otros objetos simbólicos ya conocidos.

Los ídolos de cuernos aparecen asociados a la fase calcolítica precampaniforme de ordinario, a veces con campaniforme, de un conjunto de asentamientos situados preferentemente en los tramos bajos de los ríos Tajo, Guadiana y Guadalquivir (Kalb y Höck, 1980: 99; Fig, 6; Lám. 21, a y b; Fig. 7). Presentan todos ellos una notable uniformidad en cuanto al material utilizado (barro), formas y 
dimensiones, lo que contribuye a dar la impresión de que responden a una cierta "canonicidad". Hay excepciones, como una pieza de Santa Bárbara de Casa, que reproduce la forma cónica, con base eliptica, acanaladura en la parte superior y decoración de estrias que parten de la acanaladura, recorren los laterales y se cruzan en la base, todo lo cual sugiere una sintesis entre los ídolos de cuernos y los idolos ovoidales (Piñón Varela, Bueno Ramirez, 1985: 295; Fig. 2). Otra pieza semejante procede de Aroche; es un prisma con diedros fuertemente suavizados, base elíptica y acanaladura en la parte superior, que le confiere el perfil de un ídolo de cuernos (Piñón Varela, Bueno Ramírez, 1985: 294; Fig. 3, c). También procede de Aroche otra pieza semejante a la anterior, pero de menor altura, que podría clasificarse asimismo como un tipo intermedio entre los guijarros ovoides con acanaladura y los ídolos de cuernos (Piñón Varela, Bueno Ramírez, 1985: Fig. 3, a). Las piezas onubenses citadas tienen, en comparación con éstos, la peculiaridad de estar realizadas en piedras duras en vez de barro.

Aparte de los ámbitos antes citados, el que podriamos llamar «tipo canónicon se documenta en conjuntos de la costa levantina (López Plaza, 1975: 503 y nn. 5 y 6; Lám. II) y en el estrato inferior del Morro de Mezquitilla; uno de los ejemplares hallados en este yacimiento es de forma cónica, remata en dos protuberancias verticales y bajo éstas aparecen dos rehundimientos que se interpretan como una reproducción de los «ojos", lo que subraya nuevamente su carácter de idolos, al igual que en tantos otros casos paralelos (Schubart, 1985: 146; Fig. 2, b). Para los estratos calcolíticos del Morro de Mezquitilla se propone una datación entre la segunda mitad del III milenio y los comienzos del II milenio a.C.

A propósito de estos ídolos de cuernos se ha hablado de una conexión con los altares de cuernos de El Oficio y el Cerro de la Encantada (Schubart, 1976: 188-90; Fig. 8, a; Lám. VII, a). Sin embargo, no parece que el nexo vaya más allá de una mera e incluso remota semejanza formal o tan sólo semántica, en virtud de la designación, puramente convencional, que se ha dado a los dos tipos de objetos. De admitirse que las estancias en que han aparecido los "altares" son realmente "santuarios" (Sáchez Meseguer y otros, 1985), aquéllos entrarían en la categoría de "ajuar litúrgico», sin especial significación simbólica, como ocurre con otros elementos materiales asociados al culto (soportes de grandes recipientes, hornillos, altares de ofrendas y sedes o banquetas rituales). En cualquier caso, los «altares de cuernos» hispánicos se enmarcan en un horizonte cultural -el Bronce pleno-cuyas coordenadas rituales se nos muestran, hasta donde nos es posible rastrear unas realidades ideológicas, profundamente distintas de cuanto podemos entrever para la fase eneolítica.

Para la interpretación del ídolo de Cogolludo tienen especial valor los hallazgos de piezas simbólicas en Extremadura y en la zona interior de la Península. Ya nos hemos referido al riquísimo conjunto de La Pijotilla, en que los ídolos de distintos tipos parecen asociarse a enterramientos de la fase precampaniforme del yacimiento, para la que hay una fecha radiocarbónica de 2400 a.C. Se relacionan con un extenso territorio que va de Cádiz al Alto Alemtejo, caracterizado como zona de expasión de unos prospectores de metales, al igual que las representaciones paralelas en pintura esquemáticas, que definirían otra zona de características semejantes, en concreto la integrada por la dos vertientes de Sierra Morena. Es interesante la observación de V. Hurtado en el sentido de que las influencias orientales que se constatan especialmente en los ídolos antropomorfos se ciñen a la transmisión de unas ideas más que de unos prototipos, de un complejo simbólico y religioso más que estilístico (Hurtado, 1981: 88). Tal sería el caso del ídolo de Cogolludo en relación con los paralelos aducidos. La semejanza estaría en la idea que se trata de plasmar más que en la coincidencia formal.

Recientemente se han dado a conocer otros conjuntos extremeños, como el de la Huerta de Dios (Casas de Reina, Badajoz) (Enríquez Navascués, 1983: 284-306) y el del poblado eneolítico de Los Castillejos I (Fuente de Cantos, Badajoz) (Fernández Corrales, Sauceda Pizarro, 1985: 83-100). El segundo es de interés excepcional por la abundancia de las decoraciones, mediante incisiones o dactilares, consistentes en tandas de ángulos o segmentos de círculos paralelos, que remiten con seguridad a las que ostentan los ídolos cilíndricos, sobre huesos largos o sobre falanges. También 
presentan estas piezas extremeñas la caracteristica perforación en la zona baja. El poblado de Los Castillejos I se remonta a un horizonte calcolitico y carece de elementos asignables a una etapa anterior o posterior.

Los yacimientos extremeños marcarian los jalones de la transmisión del complejo de cultura material y espiritual al que se vinculan los ídolos de cuernos y los cuernecillos de consagración (elemento que también aparece en Cagolludo); su foco originario estaría en los asentamientos fortificados del Calcolítico portugués (Delibes de Castro, 1977: 141-148).

En tierras de la Meseta, tanto al norte como al sur de la Cordillera Central, aparecen también piezas de este mismo tipo. En la submeseta Norte, a su vez, se documentan en dos zonas: la vertiente septentrional de la cordillera y la cuenca media del Duero, concretamente en la provincia de Zamora. En el primero de estos ámbitos se sitúan los yacimientos abulenses de la Peña del Aguila (Muñogalindo) y Diego Alvaro. En Muñogalindo hay piezas que corresponden a la funcionalidad de morillos, pero otra serie se ajusta a los rasgos característicos de los ídolos de cuernos, incluida la perforación parcial o completa en la zona inferior (López Plaza, 1975: 499-506; Figs. 1 y 3; Lám. I). La semejanza con los prototipos portugueses resulta más notoria en otra pieza de Diego Alvaro (López Plaza, 1975: Fig. 2, n.ํ 3), también con perforación completa y una acanaladura que recorre a lo ancho la cara frontal.

Los yacimientos zamoranos se sitúan culturalmente en un Eneolítico en trance de evolución hacia el Bronce pleno, es decir en el paso de una ganadería de ovicápridos como base económica a una agricultura progresivamente más desarrollada y especializada, que supone una paralela sedentarización. Los ídolos de cuernos hallados en los yacimientos zamoranos del Teso del Moral, en Cuelgamures (López Plaza, 1979: 99; Fig. 16, n.ํ 2), y Las Pozas (Delibes de Castro, 1985: Fig. en p. 41) serían un testimonio valioso del proceso de aculturación que experimentan las poblaciones del interior, de raiz neolítica, en el paso hacia una etapa caracterizada además por un urbanismo incipiente y el desarrollo de la metalurgia (Martínez Navarrete, 1984: 17-128). La cronología de este momento viene dada por las fechas radiocarbónicas obtenidas para Las Pozas, entre los años 2475 y 2125 a.C.

También al sur de la Cordillera Central han aparecido estas piezas, concretamente en yacimientos cercanos a Madrid. En el Castillo de Barajas (Martínez Navarrete. 1987: 58-81; Fig. en p. 68) se dan los mismos tipos que en Muñogalindo, es decir piezas troncocónicas y otras con el característico rehundimiento en la parte superior; de las dos publicadas en fotografía, una muestra, además del rehundimiento, la característica perforación en la zona baja. También en el poblado de "fondos de cabaña" de El Capricho, correspondiente a la fase precampaniforme, se documentan piezas semejantes; una de ellas se describe como "morillo troncopiramidal con ligero rehundimiento". Para la datación de estos hallazgos se toman como referencia las fechas radiocarbónicas obtenidas para la fase precampaniforme de El Ventorro, que la sitúan entre 2240 y 1930 a.C. (Martínez Navarrete, 1987: 69-70, 72).

\section{CONCLUSION}

De las anteriores consideraciones se desprende que la pieza escultórica de Cogolludo, por la materia en que está confeccionada, así como por los rasgos que se plasmaron en ella, no responde a una finalidad utilitaria, sino que se enmarca en un conjunto de obras plásticas de intencionalidad simbólica. En su estado natural, el bloque calcáreo sugería ya la acanaladura característica de los ídolos ovoides, pero esta sugerencia se completó asimilándolo, en la medida en que la forma original lo permitía, a los ídolos de cuernos, que generalmente se toman como expresión de las mismas ideas que materializan otras series, como la de los ídolos falange. 
El ídolo de Cogolludo, como los restantes a que se asemeja, se enmarca en un horizonte cultural eneolítico, representado en El Lomo por varios fondos de cabaña o, mejor dicho, elementos de habitación que han aportado otros materiales, principalmente cerámicas y utillaje de hueso y sílex, paralelos de los conjuntos más antiguos descubiertos en las terrazas de los ríos que afluyen al Tajo por su margen derecha.

La peculiar situación de Cogolludo, muy al norte del Tajo, aunque con acceso inmediato al Henares, y a la vez próximo a las estribaciones meridionales de la Cordillera Central, precisamente en el tramo de la misma que ofrece pasos más fáciles hacia la cuenca del Duero, deja pendiente la cuestión de los caminos por los que llegan a esta zona los influjos originados en la densa concentracción de asentamientos calcolíticos del Estuario del Tajo. Hay, sin embargo, indicios suficientes para que resulte más aceptable la hipótesis de que Cogolludo enlaza más bien con los complejos de la Meseta Norte para esta etapa (El Lomo I), si bien en un desarrollo ulterior (El Lomo II) se acusa más decididamente el influjo mediterráneo, ya en la fase del Bronce pleno.

\section{BIBLIOGRAFIA}

Almagro Basch, M. (1969): "El "idolo de Ciudad Rodrigo" y el "idolo de Rodicol" ". Trabajos de Prehistoria, 26: 321-326.

- (1970): «El idolo de Puig Pelegrí. Léridan. Trabajos de Prehistoria, 27: 169-176.

- (1971): «El idolo de Noceda. León». Trabajos de Prehistoria, 28: 305-312.

Almagro Gorbea, M. J. (1973): «Los ídolos del Bronce I Hispánico». Bibliotheca Praehistorica Hispana XII. Madrid. DeliBES DE CASTRO, G. (1977): „Poblamiento eneolitico en la Meseta Nortew. Sautuola, II: 141-151.

- (1985): «El Calcolitico». En Historia de Castilla y León, I. Valladolid: 36-56.

Diamant, St. y Rutrer, J. (1969): «Horned objets in Anatolia and the Near East and possible connections with the Minoan Horns of Consecration». Anatolian Studies, 19: 147-177.

EnRíuez Navascues, J. J. (1983): „Dos ídolos sobre hueso largo procedentes de Huerta de Dios». Trabajos de Prehistoria, 40: 284-306.

Fernández Corrales, J. M. y Sauceda Pizarro, M. I. (1985): «Los idolos de cuernos de Los Castillejos I. Fuente de Cantos (Badajoz)». En Tres Estudios sobre el Calcolitico extremeño: 83-100. Cáceres.

Fernández Gómez F. y Oliva Alonso, D. (1980): «Los idolos calcolíticos del Cerro de la Cabeza (Valencina de la Concepción, Sevilla)w. Madrider Mitteilungen, 21: 20-44.

GARRIDO Rolz, J. P. (1971): «Los poblados del Bronce I hispánico del estuario del Tinto-Odiel y la secuencia cultural megalítica en la región de Huelvaw. Trabajos de Prehistoria, 28: 93-108.

Hurtado, V. (1978): «Los ídolos calcoliticos de La Pijotilla (Badajoz)». Zephyrus, XXX-XXXI: 165-203.

- (1980): «Los idolos calcolíticos en el Occidente peninsulan. Habis, 9: 357-364.

- (1981): «Las figuras humanas del yacimiento de La Pijotilla (Badajoz)». Madrider Mitteilungen, 22: 78-88.

KAlB, PH. y Hock, M. (1980): «Cabeço da Bruxa, Alpiarça (Distrikt Santarém)». Madrider Mitteilungen, 21: 91-104.

Liz Callejo, C. (1975): «Un nuevo yacimiento del Bronce I en la Meseta Norte». Actas del XIV Congreso Nacional de Arqueología (Vitoria, 1975): 333-340. Zaragoza.

López Plaza, M. S. (1975): «Morillos y objetos de culto de la Edad del Bronce hallados en Muñogalindo (Avila)». Actas del XIII Congreso Nacional de Arqueología (Huelva, 1973): 499-506. Zaragoza.

- (1979): «Aportación al conocimiento de los poblados eneolíticos del SO de la Meseta Norte española: La cerámicaw. Setübal Arqueológica, V: 67-102.

Martínez Navarrete, M. I. (1984): «El comienzo de la Metalurgia en la Provincia de Madrid: la Cueva y el Cerro de Juan Barbero (Tielmes)». Trabajos de Prehistoria, 41: 17-128.

- (1987): «Los primeros períodos metalúrgicosw. 130 años de arqueología madrileña: 59-81. Madrid.

Martín Socas, D. y Camalich Massieu, M. D. (1982): «La “cerámica simbólica” y su problemática (aproximación a través de los materiales de la Colección L. Siret)». Cuadernos de Prehistoria de la Universidad de Granada, 7: 267-306.

Pinón Varela, F. y Bueno Ramirez, P. (1985): «Algunos objetos de la cultura megalítica onubense». Huelva Arqueológica, VII: 293-306.

SÁnĆHEZ MeSEgueR, J. y otros. (1985): «El altar de cuernos de La Encantada y sus paralelos orientales». Oretum, I. 125-174.

SAvory, H. N. (1968): «Spain and Portugal. The Prehistory of the Iberian Peninsulan. Londres.

- (1972): "The cultural sequence at Vila Nova de S. Pedro. A Study of the section through the innermost rampart of the Chalcolithic Castro in 1959w. Madrider Mitteilungen, 13: 23-37. 
Schubart. H. (1979): "Morro de Mezquitilla. Informe preliminar sobre la campana de excavaciones 1976". Noticiario Arqueológico Hispánico, 6: 175-218.

- (1985): "Morro de Mezquitilla. Informe preliminar sobre la campaña de excavaciones de 1982, realizada en el asentamiento fenicio cerca de la desembocadura del rio Algarrobon. Noticiario Arqueológico Hispánico, 23: 141-174.

SPINDLER, K. (1971): «Eine kupferzeitliche Siedlung vom Pico Agudo/Portugal». Madrider Mitteilungen, 12: $51-71$.

Valiente Malla, J. (1983): "Un poblado de la Edad del Bronce en El Lomo de Cogolludon. Wad-Al-Hayara, 10: $25-47$.

- (1986): «Colgantes y amuletos hallados en las terreras del río Henares». Trabajos de Prehistoria, 43: 195-209.

- (1987): «El poblado de la Loma del Lomo (Cogolludo, Guadalajara). Enterramientos de rito argárico en la Mesetan. Revista de Arqueología, VIII, 73: 34-43. 

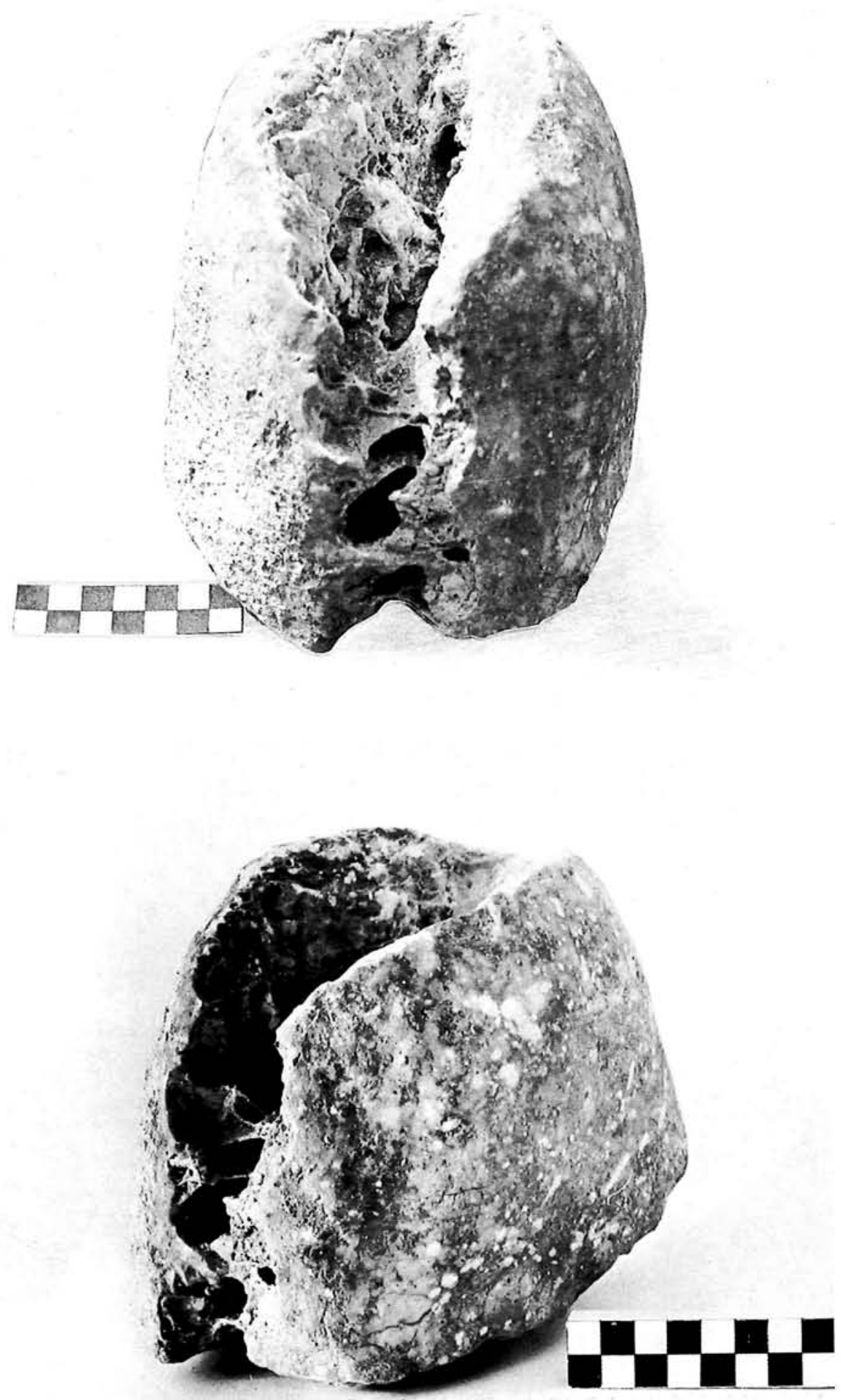

Dos vistas del ídolo de Cogolludo. 

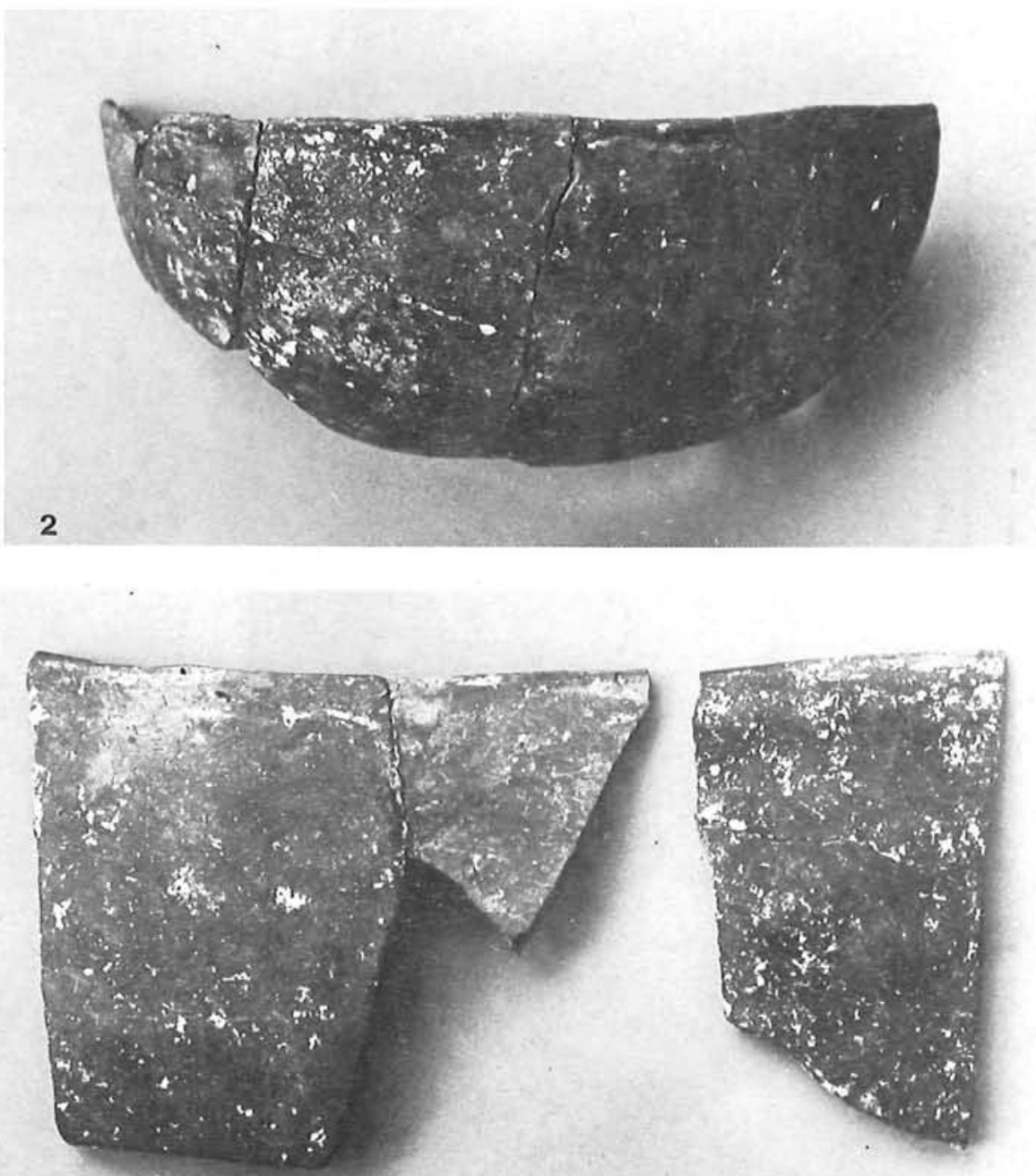

5

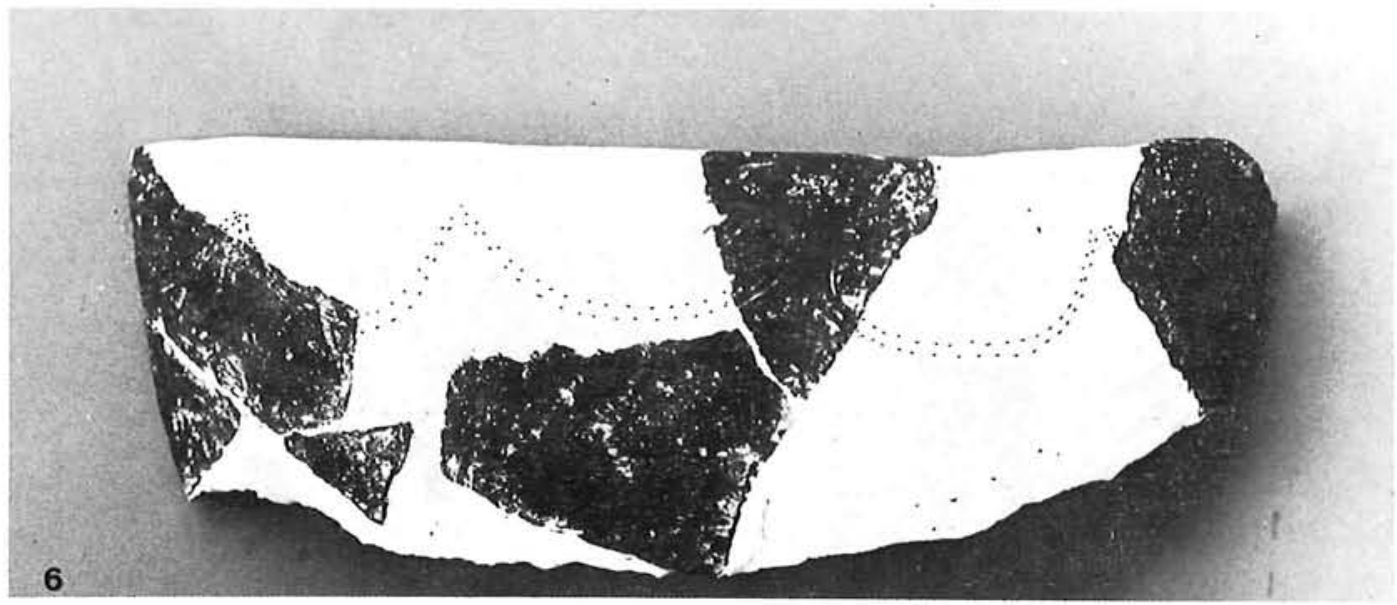

Materiales cerámicos de la hoja 14E-1 de "El Lomo» (Cogolludo, Guadalajara). 